Article

\title{
Credit Risk Assessment Model for Small and Micro-Enterprises: The Case of Lithuania
}

\author{
Rasa Kanapickiene ${ }^{1, *}$ and Renatas Spicas ${ }^{2}$ \\ 1 Department of Finance, Faculty of Economics and Business Administration, Vilnius University, \\ 10222 Vilnius, Lithuania \\ 2 Kaunas Region Credit Union, 44249 Kaunas, Lithuania; renatas.spicas@gmail.com \\ * Correspondence: rasa.kanapickiene@evaf.vu.lt
}

Received: 7 April 2019; Accepted: 5 June 2019; Published: 13 June 2019

\begin{abstract}
In this research, trade credit is analysed form a seller (supplier) perspective. Trade credit allows the supplier to increase sales and profits but creates the risk that the customer will not pay, and at the same time increases the risk of the supplier's insolvency. If the supplier is a small or micro-enterprise (SMiE), it is usually an issue of human and technical resources. Therefore, when dealing with these issues, the supplier needs a high accuracy but simple and highly interpretable trade credit risk assessment model that allows for assessing the risk of insolvency of buyers (who are usually SMiE). The aim of the research is to create a statistical enterprise trade credit risk assessment (ETCRA) model for Lithuanian small and micro-enterprises (SMiE). In the empirical analysis, the financial and non-financial data of 734 small and micro-sized enterprises in the period of 2010-2012 were chosen as the samples. Based on the logistic regression, the ETCRA model was developed using financial and non-financial variables. In the ETCRA model, the enterprise's financial performance is assessed from different perspectives: profitability, liquidity, solvency, and activity. Varied model variants have been created using (i) only financial ratios and (ii) financial ratios and non-financial variables. Moreover, the inclusion of non-financial variables in the model does not substantially improve the characteristics of the model. This means that the models that use only financial ratios can be used in practice, and the models that include non-financial variables can also be used. The designed models can be used by suppliers when making decisions of granting a trade credit for small or micro-enterprises.
\end{abstract}

Keywords: trade credit; small and micro-enterprises; financial non-financial variables; risk assessment; logistic regression

\section{Introduction}

Sellers use a variety of promotional tools to increase sales. One of these is the trade credit (Afrifa and Gyapong 2017; Wang et al. 2018), which benefits both the seller and the buyer. Trade credit is "debt arising from credit sales and recorded as an account receivable by the seller and as an account payable by the buyer" (Brigham and Houston 2004). On the one hand, according to Wang et al. (2018), "trade credit has grown rapidly and become an effective tool to incentivize suppliers to increase sales and profits in supply chain management". Fabbri and Klapper (2016) state that "the traditional explanation for the existence of trade credit is that trade credit plays a nonfinancial role". On the other hand, researchers (Lin and Chou 2015; Tsuruta 2015; Fabbri and Klapper 2016; Hill et al. 2017; Shenoy and Williams 2017; Tsao 2018) argue that customers use trade credit as one of the main sources of short-term external financing.

The peculiarity of trade credit is that it involves a joint commodity-financial transaction (Pike and Cheng 2001). The supplier sells the product or service and at the same time gives the customer credit 
for the purchase. Most authors, in analyzing the concept of trade credit (Cunat 2007; Garcia-Teruel and Martinez-Solano 2010a, 2010b; Tsao 2010; Mahata and De 2016; Tsuruta 2015), emphasize the financial aspect as a key feature-the trade credit is a deferred payment for goods for a certain period of time. In the literature (Martinez-Sola et al. 2017), the deferred payment is treated as a loan to the customer, which can be compared to the loan granted by a bank. On the other hand, it is emphasized (Paul and Boden 2011) that trade credit is provided by non-financial institutions whose primary purpose is to sell their goods to customers. Having explained the complexity of the concept of trade credit, we now discuss the economic aspects of trade credit from the perspective of both the customer and the supplier.

From the customer's perspective, research (Garcia-Teruel and Martinez-Solano 2010a; Martinez-Sola et al. 2017) shows that a "trade credit is very important for firms that have more difficulty funding themselves through credit institutions as is the case for small- and medium-sized enterprises (SMEs), (i) whose access to the capital markets is very limited, and (ii) who use less external finance, especially bank finance, and (iii) rely more on short-term debt finance" (Garcia-Teruel and Martinez-Solano 2010a). It should be noted that this problem has intensified during the period of the financial crisis. As McGuinness and Hogan (2016) claim, "in the aftermath of the financial crisis in 2008, bank lending to SMEs declined significantly in most developed economies". Consequently, trade credit is particularly important for these companies.

From the supplier's perspective, according to Wang et al. (2018), by providing trade credits, the supplier encourages customers to buy more and thus increases his/her profits. However, on the other hand, the granting of trade credits increases the default risk of the suppliers themselves.

Prior studies show that a trade credit debtor (customer) in a bankruptcy process will almost certainly fail to meet the claims of its trade creditors (suppliers), thereby causing credit losses (Jacobson and von Schedvin 2015; Wang et al. 2018). Consistent with this argument, the researchers conclude that such credit losses could, in turn, influence trading creditors to become insolvent and subsequently go bankrupt. The conclusion is confirmed by Jacobson and von Schedvin's (2015) performed research, wherein scientists emphasize that corporate failures in the corporate sector result in significantly higher credit losses than in the banking sector. The findings are based on an empirical study (Jacobson and von Schedvin 2015), which states that the aggregate annual credit loss incurred by Swedish trade creditors is around 50 percent higher than Swedish bank lending to non-financial corporations. This indicates that trade creditors (suppliers) need a tool to help identify the credit risk of trade credit debtors (customers).

This issue becomes even more complicated when the trade credit debtor (customer) is an SME. The reason for this is the lack of data (Yoshino and Taghizadeh-Hesary 2014; Martinez-Sola et al. 2017) and difficulties in accessing the authentic SME Database (Yoshino and Taghizadeh-Hesary 2014), resulting in lower quality data and lower reliability of information (Tascon et al. 2018). For an example, as Ciampi and Gordini (2013) point out, unaudited financial statements and shares yield no market price (as they are not traded on exchanges), and no credit rating is evaluated, which can be attributed to the objective reasons for the lower quality data. Therefore, as claimed by Ciampi and Gordini (2013) and Tascon et al. (2018), recent research generally recognizes that SMEs require special tools for risk management, taking into account their specific characteristics. Nevertheless, the difficulty in accessing financial data and other information from SMEs is precisely the reason, according to Abdullah et al. (2016), why little research has been done on small- and medium-sized enterprises (SMEs).

Kosmidis and Stavropoulos (2014) have analyzed the literature studies conducted so far and have concluded that there are many studies carried out on the subject of financial distress signaling and corporate failure prediction. However, credit risk assessment and default prediction models are usually developed, as is common or for large enterprises (Altman 1968; Chesser 1974; Taffler and Tisshaw 1977; Zavgren 1985; Bekhet and Eletter 2014; Niklis et al. 2014; Verbraken et al. 2014; Florez-Lopez and Ramon-Jeronimo 2015; Lessmann et al. 2015; Manab et al. 2015; Fernandes and Artes 2016; Sohn et al. 2016; Sousa et al. 2016; Xiao et al. 2016; Petropoulos et al. 2016). 
It is recognized that SMEs are an important part of the economy and their specificity in managing credit risk must be taken into account. However, there are significantly fewer models of credit risk management (Tascon et al. 2018; Zhu et al. 2016; Yoshino and Taghizadeh-Hesary 2014; Ciampi and Gordini 2013; Behr and Guettler 2007; Altman and Sabato 2007). Knowing that SMEs are generally riskier than large corporations (Yoshino and Taghizadeh-Hesary 2014; Terdpaopong and Mihret 2011), researchers (Terdpaopong and Mihret 2011) suggest using financial distress prediction models applied for SMEs.

Two areas of research can be distinguished in Lithuania. First, there are already tested credit risk and bankruptcy prediction models. The most common tested models are the models of linear discriminant analysis (Altman, Springate, Taffler and Tisshaw) and logistic regression (Chesser, Zavgren). The results are contradictory. Some scientists have expressed doubts that bankruptcy prediction models developed in different countries are suitable for predicting the bankruptcy of Lithuanian enterprises, as enterprises operate under different conditions (e.g., Purvinis et al. 2005). Secondly, new models are being developed based on enterprises operating in Lithuania. One of the first Lithuanian researchers to analyze credit risk assessment methods in the context of bankruptcy forecasting was Grigaravicius (2003), who applied a logistic regression model for corporate bankruptcy prediction. Credit risk assessment models are being developed for credit institutions-banks (Valvonis 2008; Dzidzeviciute 2013) or credit unions (Spicas 2017). If the models are applied for SMEs, the samples of model development are small (Butkus et al. 2014). Thus, standard credit models are developed by financial institutions for large companies. They rely on a large amount of data. Therefore, one cannot directly transpose these models to SMEs and special tools need to be designed.

The aim of this research is to create a statistical enterprise trade credit risk assessment model for Lithuanian small and micro-enterprises (SMiE). In this research, small and micro-enterprises are understood as they are defined in 2010-2012 by the Republic of Lithuania Law on Small- and Medium-Size Business Development, i.e., enterprises that have less than 50 employees and whose financial data meet any of the selected conditions: (i) the annual revenue of the enterprise does not exceed EUR 7 million; (ii) the value of assets indicated in the statement of financial position does not exceed EUR 5 million.

The statistical enterprise trade credit risk assessment model (hereinafter referred to as the ETCRA model) is a technical tool used during the trade creditors' (suppliers') decision-making process that helps to estimate the probability of default (PD) of potential trade credit debtors (customers) by using his/her initial data and making the decision regarding the granting of the extension of payment of goods maturity.

The development of the model is based on the following provision: the model must be practically applicable; it must be designed according to the model users, i.e., the trade creditors (suppliers). As the majority of suppliers are SME enterprises, it is necessary to evaluate the fact that these enterprises face difficulties due to limited human, financial, and technological resources. Regarding these features, the model developed must exhibit special characteristics, such as simplicity, clarity of model results, and the inclusion of accessible external information (in the form of independent variables) into modelling, including financial and non-financial information. Adapting the results of the Spicas et al. (2018) study, the following requirements apply to the model being developed:

1. The accuracy of a model, i.e., the model must hold high discriminatory power.

2. The high interpretability of the results of the model.

3. The simplicity of the model. The application of the model, a periodical review, calibration, and interpretation of the model results should not require particular knowledge in the areas of statistics and information technology.

4. A probabilistic model. The result of the model must be PD (probability of default), i.e., the probability that the debtor will become insolvent within a specified period of time. 
The research focuses on three aspects of the ETCRA model formation. Firstly, when the trade creditor (supplier) (hereinafter referred to as creditor) chooses target trade credit debtors (customers) (hereinafter referred to as debtors), a segment of the modelled dependent variable must be defined. It should be noted that the definition of a dependent variable is usually related to a loss event, i.e., the definition of bad debt. Therefore, the research focuses on how to define the bad trade credit debtor (customer) (hereinafter referred to as a bad debtor). An in-depth discussion of these aspects will be provided further in the methodology of the research. Secondly, for the ETCRA model development, it is important to choose suitable independent variables, i.e., financial and non-financial variables of enterprises. Thirdly, issues regarding the methodology of model development are discussed and the opportunities of logistic regression application are analyzed.

The most important contributions of this research are that the developed ETCRA model is characterized by high interpretability of results, accuracy, and simplicity. It can also be stated that the model features flexibility, i.e., the trade creditors (suppliers) can choose to assess the trade credit debtors using only financial ratios or, additionally, non-financial variables. As these two alternatives have been analyzed in the research, it has led to the conclusion that the inclusion of non-financial variables in the model does not substantially improve the characteristics of the model.

The research analyzes the credit risk of small and micro enterprises separately. There is also the issue of, as since 2016, the information of micro-enterprises in financial statements being significantly reduced, dependent on whether the characteristics of the ETCRA model deteriorate when compared with small enterprises. An important result of the research is that having properly selected financial ratios, the characteristics of the ETCRA model of micro-enterprises do not deteriorate.

The rest of the paper is structured as follows: The subsequent section describes the limitations on the information provided by financial statements of small and micro-enterprises in Lithuania. It is followed by a section describing the methodology of the research. The next section provides the empirical results and discussion. In the last section, the concluding remarks are presented.

\section{Limitations on Information Provided by Financial Statements of Small and Micro-Enterprises}

Since the entry into force of the Business Accounting Standards in 2004 (which are drafted on the basis of European Union law and International Accounting Standards), the financial accounting regulation has fundamentally changed in Lithuania. Accounting has become much more complicated, requiring a very high level of accountant qualifications to prepare financial statements correctly. This change has also created additional difficulties for such a complex business system, as well as for entrepreneurial development in Lithuania (especially for small- and medium-sized businesses). The small and medium business accounting system was based on the notion that small- and medium-sized enterprises do not differ significantly from large companies and should follow similar accounting requirements. It should be noted that, at that time, it was understood that small businesses could not meet all the requirements for large companies and were allowed to draw up financial statements that contained less information than large companies.

The assumption, prevailing at the end XX century, currently has changed, and it has been recognized that the needs of small- and medium-sized enterprises differ. Studies conducted by the European Commission (Ramboll Management 2005) found that the smaller the company, the more costly it is to bear accounting, financial reporting, and its audit requirements. Research has confirmed that small businesses are not able to hire employees who are capable of managing their accounts properly or in preparing financial statements, and therefore need to use these services from other enterprises.

As small companies are very important for socio-economic development in Lithuania, it was decided that the accounting and financial reporting of these companies should be simplified in order to reduce the administrative burden. The structure of financial statements has changed in Lithuania again since 2016, and the amount of information included in statements of micro-enterprises has decreased markedly. Therefore, it becomes important to assess whether the amount of the available financial information is sufficient for the enterprise trade credit risk assessment of small and micro-enterprises. 
Lower requirements for financial statements of small and micro-enterprises are established in the Law on Financial Statements of Entities of the Republic of Lithuania and in National Accounting Standards (more specifically, in Business Accounting Standards (BASs)).

Article 20 of this Law provides that the set of financial statements of medium-sized and large enterprises shall consist of the following financial statements: (i) statement of financial position; (ii) statement of profit or loss; (iii) statement of cash flows; (iv) statement of changes in equity; and (v) notes ${ }^{1}$. However, the level of detail of financial statements of small and micro-enterprises is lower, meaning that (1) a set of financial statements of small enterprises shall consist of the following financial statements: (i) statement of financial position or abridged statement of financial position; (ii) statement of profit or loss; and (iii) notes. (2) Micro-enterprises can refuse drawing up notes and the set of their financial statements shall consist of the following financial statements: (i) short statement of financial position; and (ii) short statement of profit or loss.

Users of financial statements want to get as much information as possible from the financial statements. However, financial statements of a lower level of detail do not allow calculating all the desired financial ratios of the enterprise. When analyzing the small enterprises, these limitations of financial analysis appear.

Firstly, small enterprises are not entitled to generate cash flow statements. Therefore, it is impossible for these enterprises to calculate cash flow ratios. These enterprises are not entitled to generate the statement of changes in equity as well. In this way, the information about cash flows and changes in equity necessary for analysis is lost.

Secondly, small enterprises can make an abridged statement of financial position. Hence, it is impossible to estimate financial ratios that require more thorough financial data. Some examples are given. Intangible assets, tangible assets and financial assets are not grouped into smaller components and, therefore, the structure of these assets cannot be evaluated. Inventories are not grouped into smaller components, i.e., raw materials, production in progress, and finished goods, and thus cannot be evaluated. Amounts receivable within one year are not specified, thus trade debtors cannot be accurately evaluated. All liabilities are only grouped into current liabilities (i.e., amounts payable within one year and other short-term liabilities) and non-current liabilities (i.e., amounts payable after one year and other long-term liabilities). Therefore, the components of smaller liabilities, such as amounts owed to credit institutions or trade creditors cannot be evaluated (see Appendix A, Table A1).

Third, in Lithuania, both large and small enterprises that follow the Business Accounting Standards (BASs) generate profit (loss) statements of the same level of detail, i.e., equally detail all the enterprise's income and expenses of the reporting period: (1) Income is grouped into smaller components. In the statement of profit or loss, there are also presented three items of income from financing and investing activities, i.e., income from investments in the shares of parent, subsidiaries and associated entities; income from other long-term investments and loans; and other interest and similar income. (2) According to International Financial Reporting Standards (IFRSs), "expenses are sub-classified to highlight components of financial performance that may differ in terms of frequency, the potential for gain or loss and predictability" (International Financial Reporting Standards (IFRSs)). In these enterprises, the expenses are provided in the "function of expense" (also called "cost of sales") method, i.e., the expenses are classified according to their function. In the statement of profit or loss, there are presented the following expenses: cost of sales; selling expenses; general and administrative expenses; the impairment of the financial assets and short-term investments; and interest and other similar expenses. The result of other operating-profit or loss-is provided and it is not possible to estimate the income and expenses earned in this activity separately. Thus, according to Spicas et al. (2015), "it is not possible to calculate the financial ratios

1 The titles of the financial statements and financial items are used in accordance with International Financial Reporting Standards (IFRSs). 
of expenditure level because employment costs and depreciation expenses are not known. Since the depreciation is unknown, EBITDA cannot be calculated either".

When analyzing the micro-enterprises, financial analysis is more limited than in the case of small enterprises.

Firstly, micro-enterprises may not generate cash flow statements and statements of changes in equity as well. Therefore, it is impossible for enterprises to calculate cash flow ratios. Changes in equity cannot be evaluated. These enterprises may refuse to draw up an explanatory note that explains the amounts presented in other financial statements and discloses the additional material information that is not presented in them. Therefore, the amount of information analyzed is reduced.

Secondly, micro-enterprises can make a short statement of financial position. Compared to small enterprises, even less information is available in the statement of financial position of micro-enterprises. Three points can be distinguished: (i) Equity structure is not provided. Therefore, items such as capital or retained profit (loss) and related ratios cannot be evaluated during the analysis. (ii) Only two components of current assets-inventories and other current assets-are distinguished. Thus, there is no information on cash and cash equivalents, trade debtors, or short-term investments. (iii) Only two components of fixed assets are distinguished-tangible assets and other fixed assets. Here, a methodological problem of assets grouping is faced. The other fixed assets item presented in the statement of financial position of small enterprises includes (i) assets of the deferred tax on profit, (ii) biological assets, and (iii) other assets (not included in preceding items of other fixed assets). On the other hand, the other fixed assets item presented in micro-enterprises statement of financial position includes (i) intangible assets, (ii) financial assets, and (iii) other fixed assets (to the extent that this item is presented in the statement of financial position of small enterprises) items (see Appendix A, Table A1). It suggests that the nature of these items-other fixed assets—differs. Hence, the structure of the assets of micro-enterprises becomes incomparable with that of other (small, medium, or large) enterprises.

Third, as discussed above, in small enterprises, the expenses are provided in the "function of expense" (also called "cost of sales") method, i.e., the expenses are classified according to their function, whereas in micro-enterprises, the expenses are provided in the "nature of expense" method. Enterprises aggregate expenses within profit or loss according to their nature (for example, acquired stocks and used resources; expenses related to employment relations; depreciation), and do not reallocate them among functions within the entity. The IFRSs highlight that "this method may be simple to apply because no allocations of expenses to functional classifications are necessary".

However, the problem of analyzing enterprises is that the statements of profit or loss of small and micro-enterprises are based on different methods, which makes the comparison between them relatively difficult (see Appendix A, Table A2). For example, (i) small enterprises can calculate earnings before interest and taxes (EBIT) (as interest are presented separately) - this is difficult for micro-enterprises as the interest expenses are unknown; (ii) since the expenses of micro-enterprises are not grouped by function, it is not calculated at cost of sales, selling expenses, and general and administrative expenses. Therefore, no gross profit or operating profit can be calculate, and it is also not possible to calculate corresponding ratios (gross profit margin, operating profit margin).

To sum up, it can be assumed that the decline in the amount of information presented in the financial statements may reduce the accuracy of the credit risk models being created.

\section{Methodology Formation of Development of Statistical Enterprise Trade Credit Risk Assessment Model for Small and Micro-Enterprises}

The credit risk model was developed to focus on small and micro-enterprises in Lithuania. The questions regarding data collection are discussed first.

\subsection{Data Collection}

First of all, in order to organize the research, the population, sampling, the period considered, the control period, and the sample size were determined. 


\subsubsection{The Population}

As the present research is concerned with small and micro-enterprises, it is necessary to analyze the definition of these enterprises.

Small and micro-enterprises are understood as they are defined by the Republic of Lithuania Law on Small and Medium-size Business Development (2017), i.e., enterprises that have less than 50 employees and whose financial data meets any one of these conditions were selected: (i) annual revenue of the enterprise does not exceed EUR 10 million; (ii) value of assets indicated in the statement of financial position does not exceed EUR 10 million.

As we see, the size of the enterprises is defined by three parameters: the number of employees, annual revenue, and assets. Meanwhile, the Department of Statistics of the Republic of Lithuania details enterprises only by the number of employees, i.e., an enterprise is considered small as with less than 50 employees. There is also a definition of a working enterprise, i.e., an operating enterprise-an enterprise operating with a number of employees and (or) annual revenue. According to the data of the Department of Statistics of the Republic of Lithuania, the number of enterprises in operation at the beginning of 2010 in Lithuania with less than 50 employees was 60,516 (94.8\% of all the enterprises in operation in Lithuania), and at the beginning of 2013-63,075 (95.9\% of all the enterprises in operation in Lithuania). It should also be noted that the definition of a bad debtor is associated with the concept of bankruptcy; therefore, it is necessary to know the information about bankrupt enterprises. According to the data of the Department of Statistics of the Republic of Lithuania, in 2010-2012, 4311 enterprises went bankrupt or became bankrupt, i.e., 4311 bankruptcy processes had been started. Therefore, a sample of small and micro-enterprises was formed from this population for the development of the model.

\subsubsection{Sampling}

For this research, the sample of Lithuanian small and micro enterprises was provided by a credit bureau, Creditinfo Lietuva. From the population research, the sample was formed by way of random selection-the sample comprised financial and non-financial data from small and micro-enterprises over the period of 2010-2012, i.e., over the period considered.

\subsubsection{The Period Considered}

The period considered is the period over which the financial and non-financial data of the enterprises were analyzed. In this research, the period considered was 2010-2012.

At this point, it is worth explaining why, in this research, the period considered was 2010-2012. In 2010-2012, the financial statements of both small and micro-enterprises were of the same scope. As mentioned above, the information of a micro-enterprise in the financial statements has decreased significantly since 2016. Therefore, when we examine the financial statements of micro-enterprises for 2010-2012, we can study them in two ways, i.e., it is possible to analyze the amount of information used in the trade credit risk assessment (i) if the statements were not shortened; (ii) if, at that time, micro-enterprises would have provided only as much information as required after 2016.

\subsubsection{The Control Period}

At the stage of development of the ETCRA model for small and micro-enterprises (SMiE), it was necessary to properly distinguish the bad debtor from the good debtor.

Firstly, if a traditional definition of a bad debtor is used, then the bad debtor is an enterprise that went bankrupt during the period considered or delayed in paying a debt to the creditor for more than 90 days. An enterprise that does not meet these requirements is considered a good debtor. However, Spicas et al. (2018) proved that such a definition is insufficient to form a good debtor sample. Therefore, if we follow the definition of a bad debtor formulated by Spicas et al. (2018), that "an enterprise is considered a bad debtor if during the 24-month monitoring period it went 
bankrupt or delayed payment for more than 90 calendar days to any creditor (according to the available data)" (Spicas et al. 2018), it is necessary to assess the state of an enterprise in 24 months. Thus, it is not sufficient to analyze an enterprise only in the period considered. Therefore, the control period is distinguished.

Secondly, because of the specificity of activities of the small and micro-enterprises observed, the cessation of activities without announcing bankruptcy in this target segment can occur more frequently than in the segments of large and medium enterprises. Therefore, the business continuity opportunities of enterprises should be assessed in detail-additional assessment is needed to determine whether an enterprise that is not considered as a bad debtor, continued activities, and had no significant activity failure during the control period.

According to Spicas et al. (2018), the enterprises that meet at least one of the following criteria are removed from the good debtor sample; in order to form it in a way that it is made only of enterprises performing real economic and commercial activities: (1) an operating but indebted enterprise (an enterprise that during the control period continued its activities but had significant outstanding debts to the State Social Insurance Fund); (2) an actual non-operational enterprise: an enterprise that during the control period (i) according to the data from the State Social Insurance Fund, an enterprise that employs two or fewer employees; (ii) annual income of the enterprise does not exceed EUR 10,000; (iii) value of assets indicated in the statement of financial position does not exceed EUR 5000. The assessment of business continuity opportunities was carried out in the control period. In this research, the control period was 2015-2016.

\subsubsection{Sample Size}

The sample was formed from 734 enterprises of which there were

(1) Three-hundred and nine bad debtors. During the period considered (2010-2012), these enterprises either (i) went bankrupt or started bankruptcy processes, or (ii) had significant debts. Thus, these enterprises fit the definition of a bad debtor.

(2) Four-hundred and twenty-five good debtors. The enterprises that follow the good debtor sample are those which (i) did not go bankrupt or started bankruptcy processes and did not have significant debts during the period considered (2010-2012) and (ii) during the control period continued its activities (2015-2016) and had no indications of activity failure.

\subsection{Research Methodology}

The logistic regression enterprise trade credit risk assessment (ETCRA) model for small and micro-enterprises (SMiE) was formed in this research. The research consisted of two stages: independent variables were selected at first and, secondly, the logistic regression model was compiled.

\subsubsection{Selection of Independent Variables}

The most frequently analysed financial variables are relative financial ratios that are calculated from the financial statements of enterprises. Since financial reports are standardized, it was appropriate to make a collection of possible financial ratios by analyzing the ratios used in the scientific and professional literature. It was important that the final collection of financial ratios of the model contained ratios that analyzed different areas of the enterprise's activities and would differ in the way of the economic information content. Furthermore, when the possible financial ratios were selected, the information from financial statements available for analysis needed to be taken into account.

The research was a continuation of previous authors' research. In prior empirical research (Spicas et al. 2015; Spicas et al. 2018), a total of 101 different models of bankruptcy prediction and credit risk models were analyzed. The following groups of financial ratios were found to be used in the development of these models: (i) ratios of profitability, liquidity, and expenditure level groups were most commonly used; (ii) the ratios of the groups of asset structure, solvency, and asset turnover 
were used less frequently; and (iii) the ratios of tangible asset and capital market groups were used least. After the analysis of the scientific literature, 168 financial ratios were distinguished. However, because of the abridgement of the information provided by the aforementioned financial statements of Lithuanian small enterprises, only 53 financial ratios could be used in the development of a risk model (Spicas et al. 2015; Spicas et al. 2018).

From 2016, regarding the changes in the financial statement requirements for small and micro-enterprises, the amount of information in the financial statements of these enterprises decreased. Therefore, the problem of developing credit risk models is once again relevant and needs to be reconsidered.

The hypothesis $\mathrm{H} 1$ was formulated as follows: compared to small enterprises, the characteristics of the ETCRA model for micro-enterprises by providing smaller amounts of information in the financial statements has deteriorated.

Non-financial variables are ratios that show the solvency opportunities of an enterprise by the way of analysis of non-financial sources. For example, credit histories, indicators of litigation, temporary measures applied, behavior in social networks, and other significant information. Usage of non-financial ratios is directly related to outside factors, i.e., information infrastructure; therefore, the opportunities for using these ratios vary significantly in different countries. Because of this, non-financial ratios were selected according to the data available for model development and external information infrastructure.

In this research, the following non-financial ratios collected by the credit bureau, Creditinfo Lietuva, were used: number of outstanding debts; sum of outstanding debts; average term of delay of outstanding debts; number of delayed debts; sum of delayed debts; average term of delay of delayed debts; number of requests in credit bureau; and number of valid arrests.

Hypothesis $\mathrm{H} 2$ was formulated as follows: the inclusion of non-financial variables in the model substantially improves the characteristics of the model.

Furthermore, in the scientific literature, there is a unanimous agreement regarding the positive influence of the application of variable selection methods to the quality of models (Yang and Duan 2008; Mileris 2012; Cateni et al. 2012).

In this empirical stage of research, the aim was to test the financial and non-financial variables which were used in the credit risk and bankrupt determination. Sixty-one variables were used in the model development: eight non-financial and 53 financial variables (Appendix B).

Control variables. As Li (2016) indicates, three major sources of endogeneity problems are "omitted variables, simultaneity, and measurement error". To solve the endogeneity problem, it is suggested by $\mathrm{Li}$ (2016) to "include as many important and time-variant control variables as possible".

In the research, different enterprise characteristics variables are used as control variables. For example, in order to analyze the relationship between CSR (corporate social responsibility) and firm value, researchers (Li et al. 2016; Cho et al. 2019) choose firm size, leverage, and research and development expenses as the control variables. Capital expenditure ratio, ROA (return on assets), advertising expense (Li et al. 2016), book-to-market ratio, cash flows from operating activities, and the standard deviation of daily stock returns (Cho et al. 2019) are being chosen too. It is noted that a size of an enterprise is a very important control variable, which, according to Dang et al. (2018), might be measured by total assets, total sales, and market capitalization. In addition, Herrador-Alcaide and Hernandez-Solis (2019) suggest that the size of the enterprise can be measured by the number of employees.

In this research, financial ratios, such as leverage, ROA, the logarithm of total assets, and the logarithm of total sales were selected as financial variables. Financial data, such as research and development expenses and cash flows from operating activities, were not published and were hardly collected in the SMiE financial statements. Since most SMiE enterprises do not trade shares on the stock exchange, market ratios could not be calculated. Therefore, the size of the enterprise selected as a control variable was measured by the number of employees. 
Selection of independent variables was performed as follows:

Firstly, the analysis of missing values was performed. According to Spicas et al. (2018), the number of missing values of independent variables are to be analyzed as well as the reasons behind the failure to calculate the ratio. In cases when the ratio could not be calculated, since in financial statements of a significant part of enterprises there were no data required to calculate the variable in question, the question of removal of such a ratio was addressed.

Secondly, an analysis of the discriminatory power of independent variables was performed. In a two-way analysis, the evaluation of individual discriminatory qualities of ratios and an information value method is usually applied (Yap et al. 2011; Nikolic et al. 2013):

$$
I V=\sum_{i=1}^{n}\left(\left(\frac{G_{i}}{\sum_{i=1}^{n} G_{i}}-\frac{B_{i}}{\sum_{i=1}^{n} B_{i}}\right) \cdot W O E_{i}\right),
$$

where $I V$ denotes information value indicator, $B$ is the number of bad debtors, $G$ is the number of good debtors, $n$ is the number of assessed debtors, $i$ is the the index of the attribute being evaluated, and WOE is the weight of evidence, calculated according to the second formula (Yap et al. 2011; Nikolic et al. 2013):

$$
W O E_{i}=\ln \left(\left(\frac{G_{i}}{\sum_{i=1}^{n} G_{i}}\right) /\left(\frac{B_{i}}{\sum_{i=1}^{n} B_{i}}\right)\right) .
$$

The analysis was performed for every variable by calculating the information value (IV) indicator according to the first formula. According to Siddiqi (2006), estimated IV should be interpreted as follows: (i) almost no predictive power is $I V<0.05$; (ii) poor predictive power is $0.05<I V<0.1$; (iii) medium predictive power is $0.1<I V<0.25$; (iv) high predictive power is $I V>0.25$. Typically, any characteristic with an information value of over 0.1 will be considered for inclusion into the model (Hand and Henley 1997).

Finally, the expediency of the variables included in the model was substantiated. Financial ratios were grouped in the following groups: profitability, liquidity, solvency, activity, and structure ratio groups. It was analyzed in terms of what ratios should be included in the model from each group. The possibility of removing some strongly correlated ratios from the model was considered. The remaining variables were used to compile a logistic regression model.

\subsubsection{Development of the Logistic Regression Model}

The on-going statistical ETCRA model for small and micro-enterprises (SMiE) shall evaluate the probability that a debtor "will show some undesirable behaviour in the future" (Lessmann et al. 2015). It evaluates how likely an applicant is to default (Lessmann et al. 2015).

Logistic regression is a standard statistical model which is particularly appropriate here. Indeed, scientists agree that the statistical models based on logistic regression are widely used in credit risk analysis for their efficiency (Zhu et al. 2016), reliability (Figini et al. 2017), and ease of interpretation (Han et al. 2018; Figini et al. 2017). Crone and Finlay (2012) state that "the main reason for continuing usage of the logistic regression over other methods of estimation is that it provides a suitable balance of accuracy, efficiency and interpretability of the results". In addition, this method is simple and universal (Han et al. 2018). Finally, it is indicated that logistic regression is the industry standard (Lessmann et al. 2015). The logistic regression method is used in credit risk models for small- and medium-sized enterprises (Figini et al. 2017; Zhu et al. 2016; Altman and Sabato 2007; Behr and Guettler 2007). In this research, logistic regression was selected for its popularity for default prediction.

The logistic regression ETCRA model was formed by calculating the coefficients of the selected independent variables. The logistic regression model is written as

$$
P D=P(Y=1)=\frac{1}{1+e^{-z}}, z=\beta_{0}+\beta_{1} X_{1} \ldots \beta_{k} X_{k}
$$


where the dependent variable in logistic regression $(P D=$ probability of default $)$ is a dummy variable. The $P D$ takes the value $1(Y=1)$ if a debtor defaulted in the observation period and $0(Y=0)$ otherwise (Behr and Guettler 2007); $\beta_{i}$ represents the particular coefficient in a linear combination of $k$ independent variables $(i=1, \ldots, k)$. Independent variables $X_{i}$ are all potentially relevant parameters that may drive credit risk (Behr and Guettler 2007). In this research, independent variables $X_{i}$ are financial variables, non-financial variables, and the control variable.

In the research, the forward method was applied. Initially, the constant was concluded, and the independent variables, i.e., financial ratios that have a strong correlation with the dependent variable, were gradually applied in the model. Furthermore, the expert method was considered, i.e., each group of financial ratios was analyzed, the relationships between the ratios were analyzed, and only then insignificant ratios were eliminated. The model was considered to be appropriate when the following requirements were complied with: (i) chi-square criterion $p$-value was less than 0.05; (ii) Cox and Snell R Square and Nagelkerke R Square were not less than 0.2; (iii) statistically significant variables should be included in the model, i.e., $p$-values of Wald's $p$-value were less than 0.05 .

For the measure of the predictive accuracy of the models, the receiver operating characteristic (ROC) curve was applied. This analysis was widely used (Behr and Guettler 2007; Chang et al. 2018; Figini et al. 2017). According to Crook et al. (2007), "the ROC curve is a plot of the proportion of bads classified as bad against the proportion of goods classified as bad" at all cut-off points. The former is called sensitivity and the latter is 1-specificity, since specificity is the proportion of goods predicted to be good". Han et al. (2018) refer to the area under the curve (AUC) which can be used as an indicator to quantify "a quantitative performance measure: the area will range from 0.5 , for a worthless model, to 1 , for a perfect classifier". According to Zhu et al. (2016), if $0.8<\mathrm{AUC}<0.9$, the model has excellent discriminatory power; if AUC $>0.9$, the model has outstanding discriminatory power.

Statistical analyses were performed using IBM SPSS Statistics version 25.

\section{Research Results and Findings}

As stated above, in this research the model development started with 61 variables: eight non-financial and 53 financial variables (Appendix B). One control variable, i.e., the number of employees that describes the size of the enterprise, was selected.

\subsection{Selection of Independent Variables}

During the formation of a logistic regression ETCRA model, the selection of independent variables was carried out in the order of priority described in the methodology:

Firstly, data sets with missing values and implausible information were eliminated from the sample. During the analysis of the missing values, six variables were removed (see Appendix B): inventories/sales (INV/S), accounts receivable/sales (AR/S), sales/fixed assets (S/FA), working capital/operating expenses (WC/OE), EBIT/interest expenses (EBIT/IE), and accounts receivable/inventories (AR/INV).

Secondly, during an analysis of the discriminatory power of independent variables, it was indicated that the calculated information value (IV) indicator showed that two variables by medium and 16 (eight financial ratios and eight non-financial ratios) by weak discriminatory power.

Financial variables with (i) weak discriminatory power and (ii) with medium discriminatory power were removed from further study (see Appendix B). Even though non-financial variable IV $<0.03$, i.e., the variables had weak discriminatory power, it was decided to remove only one financial variable from the further process, i.e., a number of requests in credit bureau (NRCB). In total, during this stage of analysis, 11 indicators were removed from further study, and 43 variables were chosen for further analysis: seven non-financial variables and 36 financial variables (see Appendix B).

Thirdly, financial ratios were grouped. As mentioned earlier, not all financial ratios are calculated by micro-enterprises, since at present, normative documents allow these companies to provide less information in their financial statements (see Appendix A). The ratios analyzed are as follows (see Appendix B): (1) profitability ratios (profitability ratios were divided into two groups: return of 
sales and return of investment; in this group, three ratios were not calculated for micro-enterprises); (2) liquidity ratios (in this group, seven ratios were not calculated for micro-enterprises); (3) solvency ratios (in this group, one ratio was not calculated for micro-enterprises); (4) activity ratios (in this group, one ratio was not calculated for micro-enterprises); (5) structure ratios (these ratios were divided into two groups: total assets structure ratios and equity and liabilities structure ratios; in this group, three ratios were not calculated for micro-enterprises).

These groups of financial ratios are important for trade creditors (suppliers). Indubitably, the creditor is primarily interested in the ability of the trade credit debtor (customer) to pay its current liabilities; therefore, the creditor is interested in the liquidity ratios. However, not only the liquidity of the enterprise is important, but also a long-term perspective, i.e., whether the company will be able to pay all its liabilities. In this way, the solvency ratios become important to the creditor. On the other hand, if the enterprise does not yield enough profit, it will face the problem of repayment of debts in the future-the profitability ratios of the debtor become important for the creditor. It is also important for the creditor whether the debtor activity is efficient, i.e., whether the asset is optimally used and the expenses are well managed, therefore, the creditor is interested in the activity ratios. If the debtor funds operate in the process of production or service unreasonably, the fast cycle of the process is not ensured, which results in slowing down the income from the activity, i.e., the likelihood to overdue the payment for the creditors increases. The aim of the ETCRA model implementation was for the model to include ratios from all groups of the financial ratios.

\subsection{Logistic Regression Model}

The forward (LR) method was applied. Moreover, the expert method was applied, i.e., each group of financial ratios were analyzed, and insignificant ratios were removed only after the analysis of ratio relations.

Separate ETCRA models for small and micro-enterprises were developed during the research.

First of all, different ETCRA models were created for each group of enterprises (i) for small companies (Models SE) and (ii) for micro-enterprises (Models MiE). In addition, each group of enterprises had developed three models that differ according to the use of financial ratios and non-financial variables. Varied model variants were created using (1) only financial ratios (Model SE1 and Model MiE1), (2) financial ratios and non-financial variables. Model SE2 and Model MiE2 use financial ratios and one non-financial variable (number of valid arrests (NVA)); Model SE3 and Model MiE3 use financial ratios and two non-financial variables (number of valid arrests (NVA) and average term of delay of outstanding debts (ATDOD)).

Logistic regression models were formed by calculating the coefficients of the selected independent variables (see Table 1).

Financial ratios selected for the models encompassed the main financial areas of activity analysis of enterprises: profitability, liquidity, solvency, and activity. It was found that the probability of default of small enterprises was dependent on three relative financial ratios: EBIT/sales (EBIT/S), equity/total liabilities (Eq/TL), and sales/total assets (S/TA). Moreover, the probability of default of micro-enterprises was dependent on four relative financial ratios: net profit/sales (NP/S), current assets/current liabilities (CA/CL), Eq/TL, and S/TA (see Table 1).

EBIT/sales is one of the most important profitability ratios of the company, as it shows the profitability of the enterprise during its operating and investment cycles, however, without the evaluation of the financing policy. Since this ratio cannot be calculated by the micro-enterprises (MiE), the net profit/sales ratio, which describes the profitability of all the enterprise's activities, was chosen. This ratio proved significant as it shows whether MiE's income covers all expenses; according to it, we can decide how much funds can be directed to the development of the enterprise. 
Table 1. Logistic regression enterprise trade credit risk assessment (ETCRA) models for small (SE) and micro-enterprises (MiE).

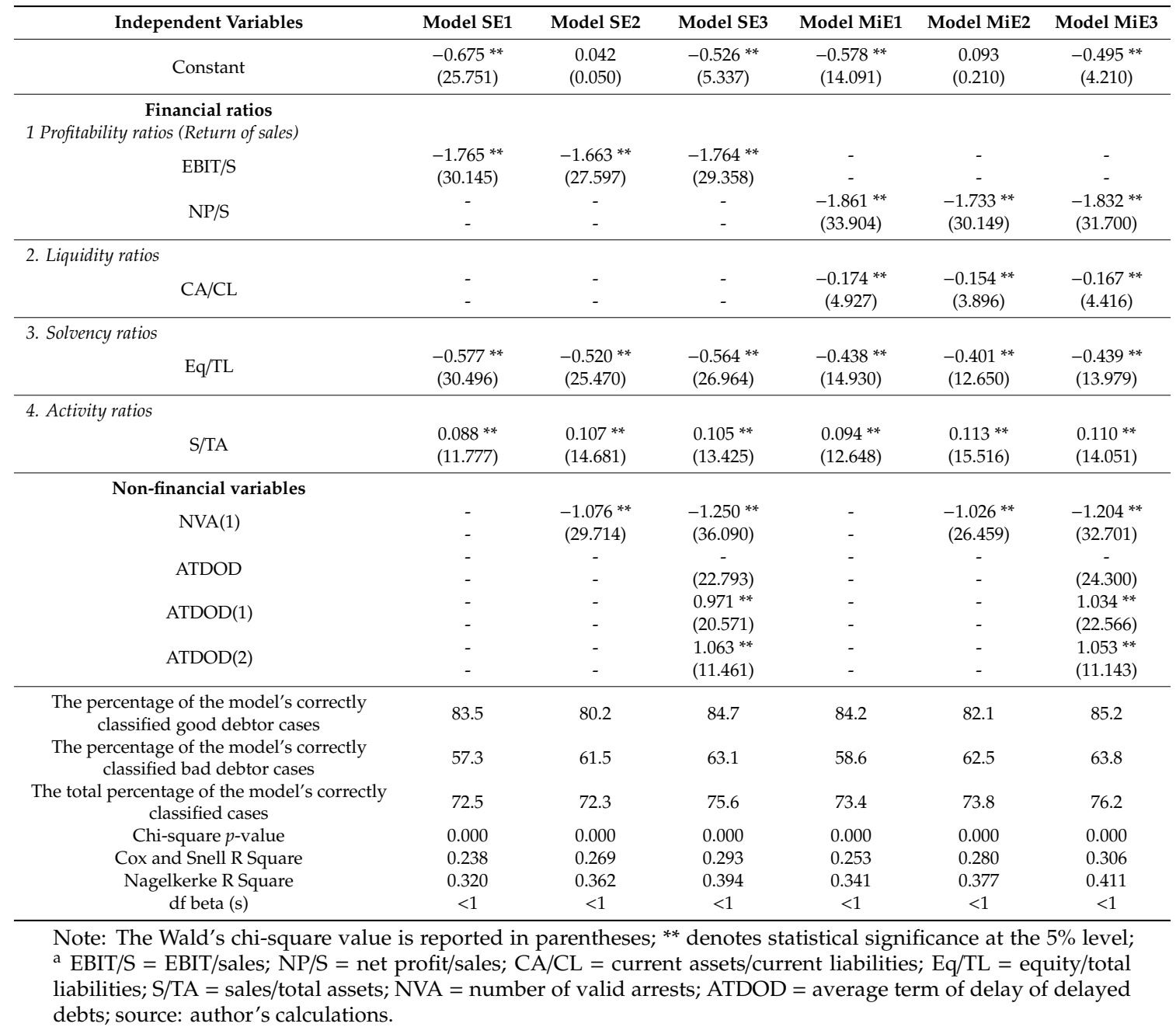

Liquidity was characterized by the current assets/current liabilities ratio, i.e., the ability of the company to meet its current liabilities using its current assets was assessed. If the enterprise already had difficulties with the payment of the current liabilities in the past year, it is likely that the current trade debts will not be covered. The solvency ratios equity/total liabilities show how many times equity is higher than total liabilities; the lower the ratio, the higher the financial risk of the enterprise, i.e., big commitments that will have to be covered in the future. The higher value of the activity ratios sales/total assets indicates a higher degree of efficiency in the overall asset management.

Compared to the research already carried out, it can be stated that the financial ratios used in the ETCRA model are widely used in the development of credit risk models. Though these ratios are widely used in global practice, they are rarely used in models created by Lithuanian enterprises. Sales/total Assets was used by Danenas et al. (2011) and Grigaravicius (2003); current assets/current liabilities_by Grigaravicius (2003), Danenas et al. (2011) and Butkus et al. (2014); equity/total liabilities—by Butkus et al. (2014).

Non-financial variables of the model analyzed credit history and other important risk factors. The probability of default was dependent on two non-financial ratios: the average term of delay of outstanding debts and number of valid arrests.

When analyzing the control variable (i.e., the size of the enterprise measured by the number of employees), it was found to be statistically insignificant, and the value of its coefficient $\beta i$ was very small, therefore, the variable was disregarded in the model. It is worth mentioning that the logarithm 
of total assets and the logarithm of total sales which were analyzed as financial variables, and may also be an enterprise size control variable, were removed from further study for weak discriminatory power. This can be explained by the fact that the model did not include enterprises of different sizes, but SMiE.

After analyzing independent variable coefficients and the weight of evidence of the developed model it can be seen that they conform to the economic logic. For example, the more effective and profitable the enterprise, the smaller the PD; a longer delay concerning repayment of debts means increased PD. If there were instances of valid seizure of assets, the PD was larger. This means that if the coefficient is positive and the independent variable increases, the probability of the event increases $(Y=1$, in this case, that an enterprise becomes insolvent) and the opposite is true as well, if the coefficient is negative as the independent variable value increases, the higher the probability that $Y=0$, i.e., that the enterprise will remain solvent. It can be stated that the developed models meet the high interpretability of results of a model.

According to the models formed, the enterprise probability of default (PD) is calculated by Equation (3), where the enterprises with $P D>50 \%$ were classified into the group of bad debtors, and the enterprises with $P D<50 \%$ were classified into the group of good debtors. According to the models formed, the calculation of coefficient $\mathrm{z}$ is shown in Appendix $\mathrm{C}$.

These models are suitable, as they comply with the following requirements: (i) chi-square criterion $p$-value is less than 0.05; (ii) Cox and Snell R Square and Nagelkerke R Square is not less than 0.2; (iii) $p$ values of Wald's $p$-value is less than 0.05 , i.e., the statistically significant variables are included in the model; (iv) the total percentage of the model's correctly classified cases is $72.3-76.2 \%$ (Table 1 ). Furthermore, Figure 1 shows ROC curves, and the area under the curves (AUC) is presented in Table 2.

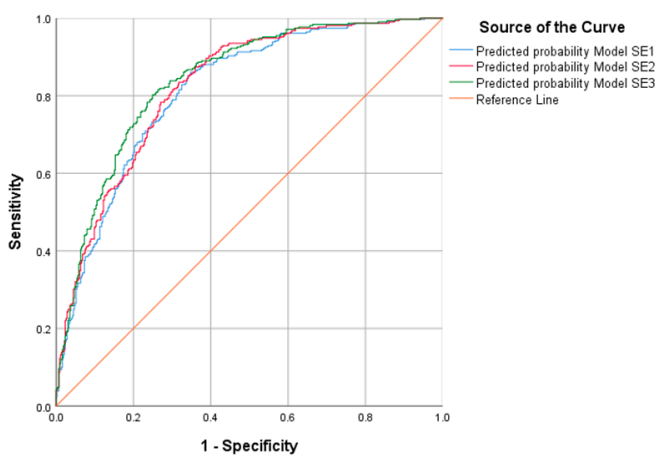

(a)

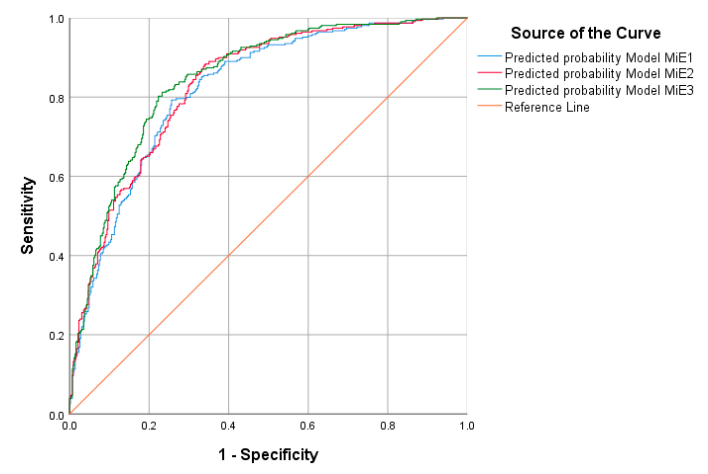

(b)

Figure 1. Receiver operating characteristic (ROC) curve: (a) for SE models; (b) for MiE models.

Table 2. Area under the curve (for SE and MiS models).

\begin{tabular}{cccccc}
\hline $\begin{array}{c}\text { Test Result } \\
\text { Variable(s): Predicted } \\
\text { Probability for }\end{array}$ & Area & Std. Error $\mathbf{a}^{\text {a }}$ & $\begin{array}{c}\text { Asymptotic } \\
\text { Sig. } \mathbf{b}\end{array}$ & \multicolumn{2}{c}{$\begin{array}{c}\text { Asymptotic 95\% } \\
\text { Confidence Interval }\end{array}$} \\
\cline { 5 - 6 } & & & & $\begin{array}{c}\text { Lower } \\
\text { Bound }\end{array}$ & $\begin{array}{c}\text { Upper } \\
\text { Bound }\end{array}$ \\
\hline Model SE1 & 0.814 & 0.016 & 0.000 & 0.783 & 0.844 \\
Model SE2 & 0.825 & 0.015 & 0.000 & 0.795 & 0.854 \\
Model SE3 & 0.840 & 0.015 & 0.000 & 0.811 & 0.868 \\
Model MiE1 & 0.821 & 0.015 & 0.000 & 0.791 & 0.851 \\
Model MiE2 & 0.831 & 0.015 & 0.000 & 0.802 & 0.860 \\
Model MiE3 & 0.847 & 0.014 & 0.000 & 0.819 & 0.875 \\
\hline
\end{tabular}

Note: ${ }^{a}$ Under the nonparametric assumption; ${ }^{\mathrm{b}}$ Null hypothesis: true area $=0.5$.

The area under the curves was 0.814 with a $95 \%$ confidence interval $(0.783,0.844)$ for Model SE1; 0.825 and $(0.795,0.854)$ for Model SE2; 0.840 and $(0.811,0.868)$ for Model SE3; 0.821 and $(0.791,0.851)$ for Model MiE1; 0.831 and $(0.802,0.860)$ for Model MiE2; 0.847 and $(0.819,0.875)$ for Model MiE3, 
respectively (see Figure 1 and Table 2). Also, the area under the curve was significantly different from 0.5 , since the $p$-value was 0.000 , meaning that the logistic regression classified the group significantly better than by chance. The formed models met the accuracy requirement: models were characterized by high discriminatory power and the AUC values were over 80 .

Finally, the models met the simplicity of a model, i.e., the application of the model and periodic review. The interpretation of the results of the model does not require particular knowledge in the field of statistics and information technologies. Therefore, trade creditors (suppliers) can use the developed ETCRA models to assess the trade credit risk of the trade credit debtors (customers). It should be noted that the data collection required to apply the models was not complicated. At the end of the financial year, enterprises are required to submit financial statements to the State Enterprise Center of Registers, and as well as this, credit and financial data of the enterprises are collected by the credit bureaus.

\section{Conclusions}

After performing the theoretical and empirical research, the following conclusions can be drawn:

- Financial and non-financial variables should be included in the statistical ETCRA models. Relative financial ratios were proposed to be used as financial variables. Non-financial variables were selected according to the data available for model development and external information infrastructure.

- Separate ETCRA models for small and micro-enterprises were developed during the research. Varied model variants have been created using (i) only financial ratios and (ii) financial ratios and non-financial variables.

- In the ETCRA model, the enterprise's financial performance is assessed from different perspectives: profitability, liquidity, solvency and activity. Profitability is expressed using the EBIT/S ratio in SE companies, and the NP/S ratio is used by MiE companies. The liquidity ratio CA/CL is used only for MiE. The solvency ratio Eq/TL and activity ratio S/TA are used in both groups of models for SE and $\mathrm{MiE}$. To assess the probability of default for the trade credit debtor (customer), two non-financial variables are suggested to be used as the non-financial variables: the number of valid arrests and the average term of delay of delayed debts.

- Both hypotheses were not confirmed during the research. Thus, (i) the inclusion of non-financial variables in the model do not substantially improve the characteristics of the model. This means that models that use only financial ratios can be used in practice, and models that include non-financial variables can also be used. (ii) Compared to small enterprises, the characteristics of the ETCRA model of micro-enterprises by providing smaller amounts of information in the financial statements do not deteriorate. ETCRA models developed during the research are suitable for both small and micro-enterprises to predict the probability of the default.

- The designed ETCRA model is probabilistic and satisfies the requirements of the results of high interpretability, accuracy, and simplicity. Therefore, this model can be used by trade creditors (suppliers) when making decisions regarding the granting a trade credit for small or micro-enterprises. In addition, the opportunity to choose is given-trade creditors (suppliers) can evaluate the trade credit debtors (customers) using only the financial ratios or, additionally, non-financial variables.

Author Contributions: Conceptualization, R.K. and R.S.; methodology, R.K. and R.S.; formal analysis, R.K. and R.S.; data curation, R.K. and R.S.; writing—original draft preparation, R.K.; writing-review and editing, R.K.; supervision, R.K.

Funding: This research received no external funding.

Acknowledgments: The authors express their gratitude to Creditinfo Lietuva for data provided for the development of statistic ECRA model.

Conflicts of Interest: The authors declare no conflict of interest. 


\section{Appendix A}

Table A1. Comparison of financial statements of enterprises of different sizes-statement of financial position.

\begin{tabular}{|c|c|c|}
\hline Medium-Sized and Large Enterprises & $\begin{array}{l}\text { Statements Generated by: } \\
\text { Small Enterprises }\end{array}$ & Micro-Enterprises \\
\hline Statement of Financial Position & $\begin{array}{c}\text { Form of a Statement: } \\
\text { Abridged Statement of Financial } \\
\text { Position }\end{array}$ & Short Statement of Financial Position \\
\hline ASSETS: & ASSETS: & ASSETS: \\
\hline FIXED ASSETS & FIXED ASSETS & FIXED ASSETS \\
\hline Intangible assets ${ }^{1}$ & Intangible assets & - \\
\hline Tangible assets ${ }^{2}$ & Tangible assets & Tangible assets \\
\hline Financial assets ${ }^{3}$ & Financial assets & - \\
\hline Other fixed assets 4 & Other fixed assets & Other fixed assets \\
\hline CURRENT ASSETS & CURRENT ASSETS & CURRENT ASSETS \\
\hline Inventories 5 & Inventories & Inventories \\
\hline Amounts receivable within one year 6 & Amounts receivable within one year & - \\
\hline Short-term investments 7 & Short-term investments & Other current assets \\
\hline Cash and cash equivalents & Cash and cash equivalents & - \\
\hline PREPAYMENTS AND ACCRUED & PREPAYMENTS AND ACCRUED & PREPAYMENTS AND ACCRUED \\
\hline INCOME & INCOME & INCOME \\
\hline EQUITY AND LIABILITIES: & EQUITY AND LIABILITIES: & EQUITY AND LIABILITIES: \\
\hline EQUITY & EQUITY & EQUITY \\
\hline Capital ${ }^{8}$ & Capital & - \\
\hline Share premium account & Share premium account & - \\
\hline Revaluation reserve & Revaluation reserve & - \\
\hline Reserves $^{9}$ & Reserves & - \\
\hline Retained profit (loss) 10 & Retained profit (loss) & - \\
\hline GRANTS, SUBSIDIES & GRANTS, SUBSIDIES & GRANTS, SUBSIDIES \\
\hline PROVISIONS ${ }^{11}$ & PROVISIONS & PROVISIONS \\
\hline AMOUNTS PAYABLE AND OTHER & AMOUNTS PAYABLE AND OTHER & AMOUNTS PAYABLE AND OTHER \\
\hline LIABILITIES & LIABILITIES & LIABILITIES \\
\hline $\begin{array}{c}\text { Amounts payable after one year and } \\
\text { other long-term liabilities } 12\end{array}$ & $\begin{array}{c}\text { Amounts payable after one year and } \\
\text { other long-term liabilities }\end{array}$ & $\begin{array}{c}\text { Amounts payable after one year and } \\
\text { other long-term liabilities }\end{array}$ \\
\hline $\begin{array}{c}\text { Amounts payable within one year and } \\
\text { other short-term liabilities } 13\end{array}$ & $\begin{array}{c}\text { Amounts payable within one year and } \\
\text { other short-term liabilities }\end{array}$ & $\begin{array}{c}\text { Amounts payable within one year and } \\
\text { other short-term liabilities }\end{array}$ \\
\hline ACCRUALS AND DEFERRED & ACCRUALS AND DEFERRED & ACCRUALS AND DEFERRED \\
\hline INCOME & INCOME & INCOME \\
\hline
\end{tabular}

The relevant items are detailed as follows: ${ }^{1}$ Assets arising from development; goodwill; software; concessions, patents, licenses, trademarks, and similar rights; other intangible assets; advance payments; ${ }^{2}$ Land; buildings and structures; machinery and plants; vehicles; other equipment, fittings, and tools; investment property (land; buildings); advance payments and tangible assets under construction (production); ${ }^{3}$ Shares in entities of the entities group; loans to entities of the entities group; amounts receivable from entities of the entities group; shares in associated entities; loans to associated entities; amounts receivable from the associated entities; long-term investments; amounts receivable after one year; other financial assets; ${ }^{4}$ Assets of the deferred tax on profit; biological assets; other assets; ${ }^{5}$ Raw materials, materials, and consumables; production and work in progress; finished goods; goods for resale; biological assets; fixed tangible assets held for sale; advance payments; ${ }^{6}$ Trade debtors; amounts owed by entities of the entities group; amounts owed by associates entities; other debtors; ${ }^{7}$ Shares in entities of the entities group; other investments; ${ }^{8}$ Authorized (subscribed) or primary capital; subscribed capital unpaid (-); own shares (-); ${ }^{9}$ Compulsory reserve or emergency (reserve) capital; reserve for acquiring own shares; other reserves; ${ }^{10}$ Profit (loss) for the reporting year; profit (loss) brought forward; ${ }^{11}$ Provisions for pensions and similar obligations; provisions for taxation; other provisions; ${ }^{12}$ Debenture loans; amounts owed to credit institutions; payments received on account; trade creditors; amounts payable under the bills and checks; amounts payable to the entities of the entities group; amounts payable to the associated entities; other amounts payable and long-term liabilities; ${ }^{13}$ Debenture loans; amounts owed to credit institutions; payments received on account; trade creditors; amounts payable under the bills and checks; amounts payable to the entities of the entities group; amounts payable to the associated entities; liabilities of tax on profit; liabilities related to employment relations; other amounts payable and short-term liabilities. 
Table A2. Comparison of financial statements of enterprises of different sizes—statement of profit or loss.

\begin{tabular}{|c|c|}
\hline $\begin{array}{c}\text { Statements } \\
\text { Large, Medium-Sized, and Small Enterprises }\end{array}$ & enerated by: \\
\hline \multicolumn{2}{|c|}{ Form of a Statement: } \\
\hline Statement of Profit or Loss & Short Statement of Profit or Loss \\
\hline Revenue & Revenue \\
\hline Cost of sales & $\begin{array}{l}\text { Acquired stocks and used resources; } \\
\text { The change in stocks value }\end{array}$ \\
\hline Fair value adjustments of the biological assets & - \\
\hline GROSS PROFIT (LOSS) & - \\
\hline Selling expenses & - \\
\hline General and administrative expenses & $\begin{array}{l}\text { Expenses related to employment relations; } \\
\text { Depreciation, amortization and impairment of assets }\end{array}$ \\
\hline Other operating results & $\begin{array}{l}\text { Other income } \\
\text { Other expenses }\end{array}$ \\
\hline $\begin{array}{l}\text { Income from investments in the shares of parent, } \\
\text { subsidiaries, and associated entities }\end{array}$ & - \\
\hline Income from other long-term investments and loans & - \\
\hline Other interest and similar income & - \\
\hline $\begin{array}{c}\text { The impairment of the financial assets and short-term } \\
\text { investments }\end{array}$ & - \\
\hline Interest and other similar expenses & - \\
\hline PROFIT (LOSS) BEFORE INCOME TAXES & - \\
\hline Income taxes & Income taxes \\
\hline NET PROFIT (LOSS) & NET PROFIT (LOSS) \\
\hline
\end{tabular}

\section{Appendix B}

Table A3. Inclusion of variables into logistic regression model for SE.

\begin{tabular}{|c|c|c|c|c|c|c|c|}
\hline \multirow{2}{*}{ Variables } & & \multirow{2}{*}{$\underset{*}{\text { Stage } 1}$} & \multicolumn{3}{|c|}{ Stage 2} & \multirow{2}{*}{$\begin{array}{c}\text { Stage } \\
3\end{array}$} & \multirow{2}{*}{$\begin{array}{c}\text { Stage } \\
4\end{array}$} \\
\hline & & & Stage 2.1 & Stage 2.2 & & & \\
\hline Non-financial variable & $\begin{array}{c}\text { Assigned } \\
\text { name }\end{array}$ & \multicolumn{6}{|c|}{ Selected (S)/Not Selected (NS) for Further Analysis } \\
\hline Number of outstanding debts & NOD & S & 0.0920 & Weak & S & S & S \\
\hline Sum of outstanding debts & SOD & $\mathrm{S}$ & 0.0430 & Weak & $\mathrm{S}$ & $\mathrm{S}$ & $\mathrm{S}$ \\
\hline Average term of delay of outstanding debts & ATDOD & $\mathrm{S}$ & 0.0540 & Weak & $\mathrm{S}$ & $\mathrm{S}$ & S \\
\hline Number of delayed debts & NDD & $\mathrm{S}$ & 0.0940 & Weak & $\mathrm{S}$ & S & S \\
\hline Sum of delayed debts & SDD & $\mathrm{S}$ & 0.0860 & Weak & $\mathrm{S}$ & $\mathrm{S}$ & S \\
\hline Average term of delay of delayed debts & ATDDD & S & 0.0870 & Weak & $S$ & S & S \\
\hline Number of requests in credit bureau & NRCB & S & 0.0340 & Weak & NS & NS & NS \\
\hline Number of valid arrests & NVA & $S$ & 0.3740 & Strong & $S$ & $\mathrm{~S}$ & $\mathrm{~S}$ \\
\hline
\end{tabular}


Table A3. Cont.

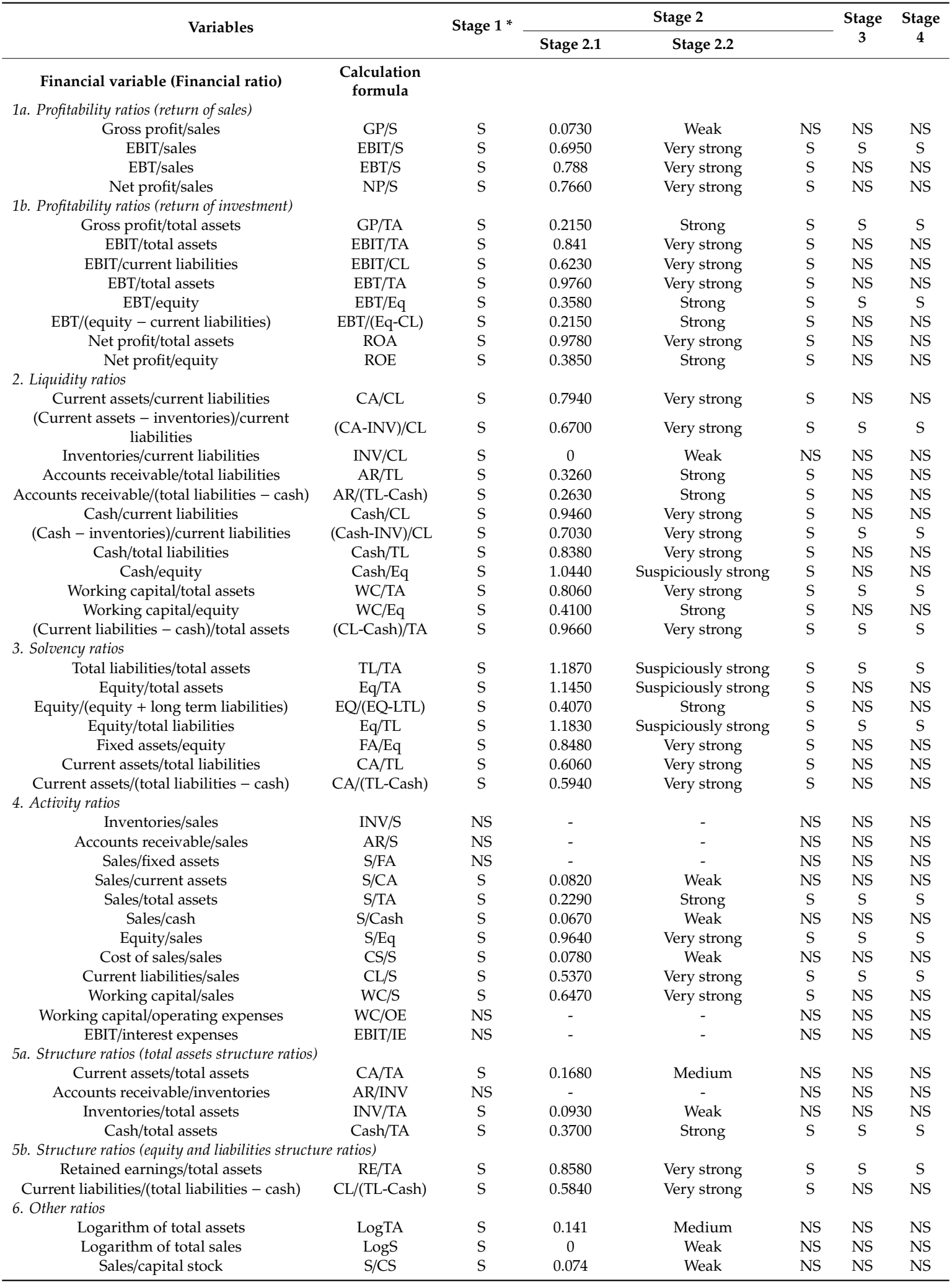

* Stage 1 -an analysis of missing values; Stage 2 -discriminatory power analysis (2.1-IV value; 2.2 -discriminatory power); Stage 3-correlation analysis; Stage 4-forward (LR) regression. 
Table A4. Inclusion of variables into logistic regression model for MiE.

\begin{tabular}{|c|c|c|c|c|c|c|c|c|}
\hline \multirow{2}{*}{ Variables } & & \multirow{2}{*}{ Stage 1} & \multicolumn{3}{|c|}{ Stage 2} & \multicolumn{2}{|c|}{ Stage 3} & \multirow{2}{*}{$\begin{array}{c}\text { Stage } \\
4\end{array}$} \\
\hline & & & $\begin{array}{c}\text { Stage } \\
2.1\end{array}$ & Stage 2.2 & & $\begin{array}{c}\text { Stage } \\
3.1\end{array}$ & $\begin{array}{l}\text { Stage } \\
3.2\end{array}$ & \\
\hline Non-financial variable & Assigned name & \multicolumn{7}{|c|}{ Selected (S)/Not Selected (NS) for Further Analysis } \\
\hline Number of outstanding debts & NOD & $\mathrm{s}$ & 0.0920 & Weak & $\mathrm{S}$ & $\mathrm{S}$ & $\mathrm{S}$ & $\mathrm{s}$ \\
\hline Sum of outstanding debts & SOD & S & 0.0430 & Weak & S & S & S & S \\
\hline $\begin{array}{c}\text { Average term of delay of outstanding } \\
\text { debts }\end{array}$ & ATDOD & S & 0.0540 & Weak & S & S & S & S \\
\hline Number of delayed debts & NDD & $\mathrm{s}$ & 0.0940 & Weak & $\mathrm{s}$ & $\mathrm{s}$ & $\mathrm{s}$ & $\mathrm{s}$ \\
\hline Sum of delayed debts & SDD & $\mathrm{S}$ & 0.0860 & Weak & $\mathrm{S}$ & $\mathrm{S}$ & $\mathrm{S}$ & $\mathrm{s}$ \\
\hline Average term of delay of delayed debts & ATDDD & $\mathrm{s}$ & 0.0870 & Weak & $\mathrm{s}$ & $\mathrm{s}$ & $\mathrm{s}$ & $\mathrm{s}$ \\
\hline Number of requests in credit bureau & NRCB & $\mathrm{S}$ & 0.0340 & Weak & NS & NS & NS & NS \\
\hline Number of valid arrests & NVA & S & 0.3740 & Strong & $\mathrm{S}$ & $\mathrm{S}$ & $\mathrm{S}$ & $\mathrm{S}$ \\
\hline Financial variable (Financial ratio) & Calculation formula & & & & & & & \\
\hline \multicolumn{9}{|l|}{ 1a. Profitability ratios (return of sales) } \\
\hline Gross profit/sales & $\mathrm{GP} / \mathrm{S}$ & S & 0.0730 & Weak & NS & NS & NS & NS \\
\hline EBIT/sales & EBIT/S & S & 0.6950 & Very strong & $\mathrm{S}$ & $\mathrm{S}$ & NS & NS \\
\hline $\mathrm{EBT} / \mathrm{sales}$ & $\mathrm{EBT} / \mathrm{S}$ & $\mathrm{s}$ & 0.788 & Very strong & $\mathrm{s}$ & $\mathrm{s}$ & NS & NS \\
\hline Net profit/sales & $\mathrm{NP} / \mathrm{S}$ & $\mathrm{S}$ & 0.7660 & Very strong & $\mathrm{S}$ & $\mathrm{S}$ & $\mathrm{S}$ & $\mathrm{S}$ \\
\hline \multicolumn{9}{|l|}{ 1b. Profitability ratios (return of investment) } \\
\hline Gross profit/total assets & GP/TA & S & 0.2150 & Strong & $\mathrm{s}$ & NS & NS & NS \\
\hline EBIT/total assets & EBIT/TA & S & 0.841 & Very strong & S & NS & NS & NS \\
\hline EBIT/current liabilities & EBIT/CL & S & 0.6230 & Very strong & $\mathrm{S}$ & NS & NS & NS \\
\hline EBT/total assets & $\mathrm{EBT} / \mathrm{TA}$ & $\mathrm{s}$ & 0.9760 & Very strong & $\mathrm{s}$ & $\mathrm{S}$ & NS & NS \\
\hline EBT/equity & $\mathrm{EBT} / \mathrm{Eq}$ & $\mathrm{s}$ & 0.3580 & Strong & $\mathrm{s}$ & $\mathrm{s}$ & $\mathrm{S}$ & $\mathrm{s}$ \\
\hline EBT/(equity - current liabilities) & $\mathrm{EBT} /(\mathrm{Eq}-\mathrm{CL})$ & S & 0.2150 & Strong & S & S & NS & NS \\
\hline Net profit/total assets & ROA & $\mathrm{s}$ & 0.9780 & Very strong & $\mathrm{S}$ & $\mathrm{s}$ & NS & NS \\
\hline Net profit/equity & ROE & S & 0.3850 & Strong & S & S & NS & NS \\
\hline \multicolumn{9}{|l|}{ 2. Liquidity ratios } \\
\hline Current assets/current liabilities & $\mathrm{CA} / \mathrm{CL}$ & $\mathrm{S}$ & 0.7940 & Very strong & S & S & S & S \\
\hline $\begin{array}{c}\text { (Current assets - inventories)/current } \\
\text { liabilities }\end{array}$ & $(\mathrm{CA}-\mathrm{INV}) / \mathrm{CL}$ & S & 0.6700 & Very strong & S & S & S & S \\
\hline Inventories/current liabilities & INV/CL & $\mathrm{s}$ & 0 & Weak & NS & NS & NS & NS \\
\hline Accounts receivable/total liabilities & $\mathrm{AR} / \mathrm{TL}$ & S & 0.3260 & Strong & $\mathrm{S}$ & NS & NS & NS \\
\hline $\begin{array}{l}\begin{array}{l}\text { Accounts receivable/(total liabilities - } \\
\text { cash) }\end{array}\end{array}$ & AR/(TL-Cash) & S & 0.2630 & Strong & S & NS & NS & NS \\
\hline Cash/current liabilities & Cash/CL & S & 0.9460 & Very strong & S & NS & NS & NS \\
\hline (cash - inventories)/current liabilities & (Cash-INV)/CL & $\mathrm{s}$ & 0.7030 & Very strong & $\mathrm{s}$ & NS & NS & NS \\
\hline Cash/total liabilities & Cash/TL & $S$ & 0.8380 & Very strong & $\mathrm{s}$ & NS & NS & NS \\
\hline Cash/equity & Cash/Eq & $S$ & 1.0440 & Suspiciously strong & S & NS & NS & NS \\
\hline Working capital/total assets & WC/TA & $S$ & 0.8060 & Very strong & S & $\mathrm{S}$ & $\mathrm{S}$ & $\mathrm{S}$ \\
\hline Working capital/equity & $\mathrm{WC} / \mathrm{Eq}$ & $\mathrm{s}$ & 0.4100 & Strong & $\mathrm{S}$ & $\mathrm{s}$ & NS & NS \\
\hline (Current liabilities - cash)/total assets & (CL-Cash)/TA & S & 0.9660 & Very strong & S & NS & NS & NS \\
\hline 3. Solvency ratios & & & & & & & & \\
\hline Total liabilities/total assets & $\mathrm{TL} / \mathrm{TA}$ & $\mathrm{s}$ & 1.1870 & Suspiciously strong & $\mathrm{S}$ & $\mathrm{s}$ & $\mathrm{s}$ & $\mathrm{s}$ \\
\hline Equity/total assets & $\mathrm{Eq} / \mathrm{TA}$ & S & 1.1450 & Suspiciously strong & $\mathrm{S}$ & S & NS & NS \\
\hline Equity/(equity + long term liabilities) & EQ/(EQ-LTL) & $\mathrm{S}$ & 0.4070 & Strong & S & S & NS & NS \\
\hline Equity/total liabilities & $\mathrm{Eq} / \mathrm{TL}$ & S & 1.1830 & Suspiciously strong & S & S & $\mathrm{S}$ & $\mathrm{S}$ \\
\hline Fixed assets/equity & $\mathrm{FA} / \mathrm{Eq}$ & $\mathrm{S}$ & 0.8480 & Very strong & $\mathrm{S}$ & $\mathrm{s}$ & NS & NS \\
\hline Current assets/total liabilities & $\mathrm{CA} / \mathrm{TL}$ & $S$ & 0.6060 & Very strong & $\mathrm{S}$ & S & NS & NS \\
\hline Current assets/(total liabilities - cash) & CA/(TL-Cash) & S & 0.5940 & Very strong & S & NS & NS & NS \\
\hline 4. Activity ratios & & & & & & & & \\
\hline Inventories/sales & $\mathrm{INV} / \mathrm{S}$ & NS & - & - & NS & NS & NS & NS \\
\hline accounts receivable/sales & $\mathrm{AR} / \mathrm{S}$ & NS & - & - & NS & NS & NS & NS \\
\hline Sales/fixed assets & S/FA & NS & - & - & NS & NS & NS & NS \\
\hline Sales/current assets & S/CA & $\mathrm{S}$ & 0.0820 & Weak & NS & NS & NS & NS \\
\hline Sales/total assets & $\mathrm{S} / \mathrm{TA}$ & S & 0.2290 & Strong & $\mathrm{S}$ & $\mathrm{S}$ & $\mathrm{S}$ & $\mathrm{S}$ \\
\hline Sales/cash & S/Cash & $\mathrm{s}$ & 0.0670 & Weak & NS & NS & NS & NS \\
\hline Equity/sales & $\mathrm{S} / \mathrm{Eq}$ & $\mathrm{s}$ & 0.9640 & Very strong & $\mathrm{s}$ & $\mathrm{s}$ & $\mathrm{s}$ & $\mathrm{s}$ \\
\hline Cost of sales/sales & $\mathrm{CS} / \mathrm{S}$ & S & 0.0780 & Weak & NS & NS & NS & NS \\
\hline Current liabilities/sales & $\mathrm{CL} / \mathrm{S}$ & $S$ & 0.5370 & Very strong & $\mathrm{S}$ & $\mathrm{S}$ & $\mathrm{S}$ & $\mathrm{S}$ \\
\hline Working capital/sales & WC/S & S & 0.6470 & Very strong & $\mathrm{S}$ & S & NS & NS \\
\hline Working capital/operating expenses & WC/OE & NS & - & - & NS & NS & NS & NS \\
\hline EBIT/interest expenses & EBIT/IE & NS & - & - & NS & NS & NS & NS \\
\hline 5a. Structure ratios (total assets structure rati & & & & & & & & \\
\hline Current assets/total assets & $\mathrm{CA} / \mathrm{TA}$ & s & 0.1680 & Medium & NS & NS & NS & NS \\
\hline Accounts receivable/inventories & AR/INV & NS & - & - & NS & NS & NS & NS \\
\hline Inventories/total assets & INV/TA & $\mathrm{S}$ & 0.0930 & Weak & NS & NS & NS & NS \\
\hline Cash/total assets & Cash/TA & S & 0.3700 & Strong & $\mathrm{S}$ & NS & NS & NS \\
\hline 5b. Structure ratios (equity and liabilities stru & ratios) & & & & & & & \\
\hline Retained earnings/total assets & $\mathrm{RE} / \mathrm{TA}$ & S & 0.8580 & Very strong & S & S & NS & NS \\
\hline Current liabilities/(total liabilities - cash) & CL/(TL-Cash) & S & 0.5840 & Very strong & S & $\mathrm{S}$ & NS & NS \\
\hline 6. Other ratios & & & & & & & & \\
\hline Logarithm of total assets & LogTA & $\mathrm{s}$ & 0.141 & Medium & NS & NS & NS & NS \\
\hline Logarithm of total sales & LogS & S & 0 & Weak & NS & NS & NS & NS \\
\hline Sales/capital stock & S/CS & S & 0.074 & Weak & NS & NS & NS & NS \\
\hline
\end{tabular}

Note: * Stage 1-An analysis of missing values; Stage 2-Discriminatory power analysis (2.1-IV value; 2.2-Discriminatory power; Stage 3.1-The ratios are not calculated for micro-enterprises; Stage 3.2-Correlation analysis; Stage 4-Forward (LR) regression. 


\section{Appendix C}

Table A5. The calculation of coefficient $z$ for the logistic regression enterprise trade credit risk assessment (ETCRA) models for small (SE) and micro-enterprises (MiE).

\begin{tabular}{|c|c|c|}
\hline $\begin{array}{l}\text { Varied Model Variants Have been Created } \\
\text { Using: }\end{array}$ & Models for SE & Models for MiE \\
\hline (1) only financial ratios & $\begin{array}{c}\mathrm{z}_{\mathrm{SE} 1}=-0.675-1.765 \times \mathrm{EBIT} / \mathrm{S}-0.577 \times \\
\mathrm{Eq} / \mathrm{TL}+0.088 \times \mathrm{S} / \mathrm{TA}\end{array}$ & $\begin{array}{c}\mathrm{z}_{\mathrm{MiE} 1}=-0.578-1.861 \times \mathrm{NP} / \mathrm{S}-0.174 \times \\
\mathrm{CA} / \mathrm{CL}-0.438 \times \mathrm{Eq} / \mathrm{TL}+0.094 \times \mathrm{S} / \mathrm{TA}\end{array}$ \\
\hline \multicolumn{3}{|l|}{$\begin{array}{l}\text { (2) financial ratios and non-financial } \\
\text { variables: }\end{array}$} \\
\hline $\begin{array}{l}\text { (i) model uses financial ratios and one } \\
\text { non-financial variable (NVA) }\end{array}$ & $\begin{array}{c}\mathrm{z}_{\mathrm{SE} 2}=0.042-1.663 \times \mathrm{EBIT} / \mathrm{S}-0.520 \times \\
\mathrm{Eq} / \mathrm{TL}+0.107 \times \mathrm{S} / \mathrm{TA}+\mathrm{k}_{\mathrm{SE} 2} *\end{array}$ & $\begin{array}{c}\mathrm{z}_{\mathrm{MiE2}}=0.093-1.733 \times \mathrm{NP} / \mathrm{S}-0.154 \times \\
\mathrm{CA} / \mathrm{CL}-0.401 \times \mathrm{Eq} / \mathrm{TL}+0.113 \times \mathrm{S} / \mathrm{TA} \\
+\mathrm{k}_{\mathrm{MiE} 2}\end{array}$ \\
\hline $\begin{array}{l}\text { (ii) model uses financial ratios and two } \\
\text { non-financial variables (NVA and ATDOD) }\end{array}$ & $\begin{array}{c}\mathrm{z}_{\mathrm{SE} 3}=-0.526-1.764 \times \mathrm{EBIT} / \mathrm{S}-0.564 \times \\
\mathrm{Eq} / \mathrm{TL}+0.105 \times \mathrm{S} / \mathrm{TA}+\mathrm{k}_{\mathrm{SE} 3}{ }^{*}+\mathrm{n}_{\mathrm{SE}}{ }^{* *}\end{array}$ & $\begin{array}{c}\mathrm{z}_{\mathrm{MiE} 3}=-0.495-1.832 \times \mathrm{NP} / \mathrm{S}-0.167 \times \\
\mathrm{CA} / \mathrm{CL}-0.439 \times \mathrm{Eq} / \mathrm{TL}+0.110 \times \mathrm{S} / \mathrm{TA}+ \\
\mathrm{k}_{\mathrm{MiE} 3}{ }^{*}+\mathrm{n}_{\mathrm{MiE}} * *\end{array}$ \\
\hline${ }^{*} k$ denotes number of valid arrests & $\begin{array}{l}\text { Model SE2: if NVA }>0: \mathrm{k}_{\mathrm{SE} 2}=-1.076 \text {, } \\
\text { if not-0; } \\
\text { Model SE3: if NVA }>0: \mathrm{k}_{\mathrm{SE} 3}=-1.250, \\
\text { if not }-0\end{array}$ & $\begin{array}{l}\text { Model MiE2: if NVA }>0: \mathrm{k}_{\mathrm{MiE} 2}=-1.026, \\
\text { if not-0; } \\
\text { Model MiE3: if NVA }>0: \mathrm{k}_{\mathrm{MiE} 3}=-1.204, \\
\text { if not-0 }\end{array}$ \\
\hline $\begin{array}{l}* * n \text { describes the average term of delay of } \\
\text { outstanding debts }\end{array}$ & $\begin{array}{l}\text { when delayed payment for more than } \\
90 \text { calendar days, } \mathrm{n}=0 \text {; when an enterprise } \\
\text { does not have delayed payment, } \\
\mathrm{n}_{\mathrm{SE}}=0.971 ; \text { in over case } \mathrm{n}_{\mathrm{SE}}=1.063\end{array}$ & $\begin{array}{c}\text { when delayed payment for more than } \\
90 \text { calendar days, } \mathrm{n}=0 \text {; when an enterprise } \\
\text { does not have delayed payment, } \\
\mathrm{n}_{\mathrm{MiE}}=1.034 ; \text { in over case } \mathrm{n}_{\mathrm{MiE}}=1.053\end{array}$ \\
\hline
\end{tabular}

\section{References}

Abdullah, Nur Adiana Hiau, Muhammad M. Ma'aji, and Hwei Khaw. 2016. The value of governance variables in predicting financial distress among small and medium-sized enterprises in Malaysia. Asian Academy of Management Journal of Accounting and Finance 12: 77-91. [CrossRef]

Afrifa, Godfred Adjapong, and Ernest Gyapong. 2017. Net trade credit: What are the determinants? International Journal of Managerial Finance 13: 246-66. [CrossRef]

Altman, Edward. 1968. Financial Ratios, Discriminant Analysis and the Prediction of Corporate Bankruptcy. Journal of Finance 23: 589-609. [CrossRef]

Altman, Edward, and Gabriele Sabato. 2007. Modelling credit risk for SMEs: Evidence from the US market. ABACUS-A Journal of Accounting Finance and Business Studies 43: 332-57. [CrossRef]

Behr, Patrick, and Andre Guettler. 2007. Credit risk assessment and relationship lending: An empirical analysis of German small and medium-sized enterprises. Journal of Small Business Management 45: 194-213. [CrossRef]

Bekhet, Hussain Ali, and Shorouq Fathi Kamel Eletter. 2014. Credit risk assessment model for Jordanian commercial banks: Neural scoring approach. Review of Development Finance 4: 20-28. [CrossRef]

Brigham, Eugene, and Joel Houston. 2004. Fundamentals of Financial Management, 10th ed. Mason: Thomson/ South-Western.

Butkus, Mindaugas, Sigita Žakarè, and Diana Cibulskienè. 2014. Bankruptcy diagnostic model and its application to predict company's bankrupt likelihood in Lithuania. Applied Economics: Systematic Research 8: 111-32.

Cateni, Silvia, Marco Vannucci, Marco Vannocci, and Valentina Colla. 2012. Variable Selection and Feature Extraction through Artificial Intelligence Techniques. In Multivariate Analysis in Management, Engineering and Science. Edited by Valim de Freitas and A. P. Barbosa Rodrigues de Freitas. London: INTECH, vol. 6, pp. 103-17. [CrossRef]

Chang, Yung-Chia, Kuei-Hu Chang, and Guan-Jhih Wu. 2018. Application of eXtreme gradient boosting trees in the construction of credit risk assessment models for financial institutions. Applied Soft Computing 73: 914-20. [CrossRef]

Chesser, Delton. 1974. Predicting loan noncompliance. Journal of Commercial Bank Lending 58: 28-38.

Cho, Sang Jun, Chune Young Chung, and Jason Young. 2019. Study on the Relationship between CSR and Financial Performance. Sustainability 11: 343. [CrossRef] 
Ciampi, Francesco, and Niccolo Gordini. 2013. Small Enterprise Default Prediction Modeling through Artificial Neural Networks: An Empirical Analysis of Italian Small Enterprises. Journal of Small Business Management 51: 23-45. [CrossRef]

Crone, Sven F., and Steven Finlay. 2012. Instance sampling in credit scoring: An empirical study of sample size and balancing. International Journal of Forecasting 28: 224-38. [CrossRef]

Crook, Jonathan, David Edelman, and Lyn Thomas. 2007. Recent developments in consumer credit risk assessment. European Journal of Operational Research 183: 1447-65. [CrossRef]

Cunat, Vicente. 2007. Trade Credit: Suppliers as Debt Collectors and Insurance Providers. The Review of Financial Studies 20: 491-527. [CrossRef]

Danenas, Paulius, Gintautas Garsva, and Rimvydas Simutis. 2011. Development of Discriminant Analysis and Majority-Voting Based Credit Risk Assessment Classifier. In Paper presented at Proceedings of the 2011 international Conference on Artificial Intelligence, ICAI, Las Vegas, NV, USA, July 18-21; vol. 1, pp. $204-9$.

Dang, Chongyu, Zhichuan (Frank) Li, and Chen Yang. 2018. Measuring Firm Size in Empirical Corporate Finance. Journal of Banking \& Finance 86: 159-76.

Dzidzeviciute, Laima. 2013. Possibilities of the Statistical Scoring Models' Application at Lithuanian Banks. Ph.D. dissertation, Vilnius University, Vilnius, Lithuania; 237p.

Fabbri, Daniela, and Leora F. Klapper. 2016. Bargaining power and trade credit. Journal of Corporate Finance 41: 66-80. [CrossRef]

Fernandes, Guilherme, and Rinaldo Artes. 2016. Spatial dependence in credit risk and its improvement in credit scoring. European Journal of Operational Research 249: 517-24. [CrossRef]

Figini, Silvia, Federico Bonelli, and Emanuele Giovannini. 2017. Solvency prediction for small and medium enterprises in banking. Decision Support Systems 102: 91-97. [CrossRef]

Florez-Lopez, Raquel, and Juan Manuel Ramon-Jeronimo. 2015. Enhancing accuracy and interpretability of ensemble strategies in credit risk assessment. A correlated-adjusted decision forest proposal. Expert Systems with Applications 42: 5737-53. [CrossRef]

Garcia-Teruel, Pedro Juan, and Pedro Martinez-Solano. 2010a. Determinants of trade credit: A comparative study of European SMEs. International Small Business Journal 28: 215-33. [CrossRef]

Garcia-Teruel, Pedro Juan, and Pedro Martinez-Solano. 2010b. A Dynamic Approach to Accounts Receivable: A Study of Spanish SME s. European Financial Management 16: 400-21. [CrossRef]

Grigaravicius, Saulius. 2003. Corporate Failure Diagnosis. Reliability and Practice. Management of Organizations: Systematic Research 28: 29-42.

Han, Jun-Tae, Jae-Seok Choi, Myeon-Jung Kim, and Jina Jeong. 2018. Developing a Risk Group Predictive Model for Korean Students Falling into Bad Debt. Asian Economic Journal 32: 3-14. [CrossRef]

Hand, David J., and William E. Henley. 1997. Statistical classification methods in consumer credit scoring: A review. Journal of the Royal Statistical Society Series A-Statistics in Society 160: 523-41. [CrossRef]

Herrador-Alcaide, Teresa, and Montserrat Hernandez-Solis. 2019. Empirical Study Regarding Non-Financial Disclosure for Social Conscious Consumption in the Spanish E-Credit Market. Sustainability 11: 866. [CrossRef]

Hill, Matthew D., Gary W. Kelly, Lorenzo A. Preve, and Virginia Sarria-Allende. 2017. Trade Credit or Financial Credit? An International Study of the Choice and Its Influences. Emerging Markets Finance and Trade 53: 2318-32. [CrossRef]

International Financial Reporting Standards (IFRSs). 2008. Commission Regulation (EC) No. 1126/2008 of 3 November 2008 Adopting Certain International Accounting Standards in Accordance with Regulation (EC) No. 1606/2002 of the European Parliament and of the Council. Available online: http://eur-lex.europa.eu (accessed on 26 February 2019).

Jacobson, Tor, and Erik von Schedvin. 2015. Trade credit and the propagation of corporate failure: An empirical analysis. Econometrica 83: 1315-71. [CrossRef]

Kosmidis, Kosmas, and Antonios Stavropoulos. 2014. Corporate failure diagnosis in SMEs: A longitudinal analysis based on alternative prediction models. International Journal of Accounting and Information Management 22: 49-67. [CrossRef]

Lessmann, Stefan, Bart Baesen, Hsin-Vonn Seow, and Lyn C. Thomas. 2015. Benchmarking state-of-the-art classification algorithms for credit scoring: An update of research. European Journal of Operational Research 247: 124-36. [CrossRef] 
Li, Frank. 2016. Endogeneity in CEO power: A survey and experiment. Investment Analysts Journal 45: 149-62. [CrossRef]

Li, Frank, Tao Li, and Dylan Minor. 2016. CEO power, corporate social responsibility, and firm value: A test of agency theory. International Journal of Managerial Finance 12: 611-28. [CrossRef]

Lin, Tsung-Te, and Jian-Hsin Chou. 2015. Trade credit and bank loan: Evidence from Chinese firms. International Review of Economics \& Finance 36: 17-29.

Mahata, Gour Chandra, and Sujit Kumar De. 2016. An EOQ inventory system of ameliorating items for price dependent demand rate under retailer partial trade credit policy. Operations Research E Decision Theory OPSEARCH 53: 889-916.

Manab, Norlida Abdul, Ng Yen Theng, and Rohani Md-Rus. 2015. The Determinants of Credit Risk in Malaysia. Procedia-Social and Behavioral Sciences 172: 301-8. [CrossRef]

Martinez-Sola, Cristina, Pedro J. Garcia-Teruel, and Pedro Martinez-Solano. 2017. SMEs access to finance and the value of supplier financing. Spanish Journal of Finance and Accounting/Revista Española de Financiación y Contabilidad 46: 455-83. [CrossRef]

McGuinness, Gerard, and Teresa Hogan. 2016. Bank credit and trade credit: Evidence from SMEs over the financial crisis. International Small Business Journal 34: 412-45. [CrossRef]

Mileris, Ricardas. 2012. Assessment of enterprise default probability by credit rating model—Imoniu finansiniu ısipareigojimu neı̨vykdymo tikimybès vertinimas nustatant kredito reitingus. Applied Economics: Systematic Research 6: 127-43.

Niklis, Dimitrios, Michael Doumpos, and Constantin Zopounidis. 2014. Combining market and accounting-based models for credit scoring using a classification scheme based on support vector machines. Applied Mathematics and Computation 234: 69-81. [CrossRef]

Nikolic, Nebojsa, Nevenka Zarkic-Joksimovic, Djordje Stojanovski, and Iva Joksimovic. 2013. The application of brute force logistic regression to corporate credit scoring models: Evidence from Serbian financial statements. Expert Systems with Applications 40: 5932-44. [CrossRef]

Paul, Salima Y., and Rebecca Boden. 2011. Size matters: The late payment problem. Journal of Small Business and Enterprise Development 18: 732-47. [CrossRef]

Petropoulos, Anastasios, Sotirio Chartzis, and Stylianos Xanthopuolos. 2016. A novel corporate credit rating system based on Student's-t hidden Markov models. Expert Systems with Applications 53: 87-105. [CrossRef]

Pike, Richard H., and Nam Sang Cheng. 2001. Credit management: An examination of policy choices, practices and late payment in UK companies. Journal of Business Finance and Accounting 28: 1013-41. [CrossRef]

Purvinis, Ojaras, Povilas Sukys, and Ruta Virbickaite. 2005. Research of the Possibility of Bankruptcy Diagnostics Applying Neural Network. Engineering Economics 41: 16-22.

Ramboll Management. 2005. Report on Impacts of Raised Thresholds Defining SMEs; Stockholm. Available online: https://docplayer.net/storage/24/3408074/1560288073/UtH7rKTuqd84H219mPWwGQ/3408074.pdf (accessed on 26 February 2019).

Shenoy, Jaideep, and Ryan Williams. 2017. Trade credit and the joint effects of supplier and customer financial characteristics. Journal of Financial Intermediation 27: 68-80. [CrossRef]

Siddiqi, Naeem. 2006. Credit Risk Scorecards: Developing and Implementing Intelligent Credit Scoring. Hoboken: John Willey \& Sons.

Sohn, So Young, Dong Ha Kim, and Jin Hee Yoon. 2016. Technology credit scoring model with fuzzy logistic regression. Applied Soft Computing 43: 150-58. [CrossRef]

Sousa, Maria Rocha, João Gama, and Elísio Brandão. 2016. A new dynamic modeling framework for credit risk assessment. Expert Systems with Application 45: 341-51.

Spicas, Renatas. 2017. Statistical Credit Risk Assessment Model of Small and Very Small Enterprises for Lithuanian Credit Unions. Ph.D. dissertation, Vilnius University, Vilnius, Lithuania; 236p.

Spicas, Renatas, Rasa Kanapickiene, and Monika Ivaskeviciute. 2015. Filter Methods of Variable Selection for Enterprise Credit Risk Prediction. Paper presented at 15th International Scientific Conference on Perspectives of Business and Entrepreneurship Development-Economic, Management, Finance and System Engineering from the Academic and Practitioners Views, Brno Univ Technol, Fac Business and Management, Brno, Czech Republic, May 28-29. 
Spicas, Renatas, Rasa Kanapickiene, Mindaugas Vijunas, and Robertas Kirka. 2018. Development of Enterprise Credit Risk Assessment Model for Lithuanian Credit Unions. Transformations in Business E Economics 17: 152-77.

Taffler, Richard, and Howard Tisshaw. 1977. Going, Going, Gone-Four Factors Which Predict. Accountancy 88: 50-54.

Tascon, Maria, Francisco Castano, and Paula Castro. 2018. A new tool for failure analysis in small firms: Frontiers of financial ratios based on percentile differences (PDFR). Spanish Journal of Finance and Accounting/Revista Española de Financiación y Contabilidad 47: 433-63. [CrossRef]

Terdpaopong, Kanitsorn, and Dessalegn Getie Mihret. 2011. Modelling SME credit risk: Thai Empirical evidence. Small Enterprise Research 18: 63-79. [CrossRef]

Tsao, Yu-Chung. 2010. Two-phase pricing and inventory management for deteriorating and fashion goods under trade credit. Mathematical Methods of Operations Research 72: 107. [CrossRef]

Tsao, Yu-Chung. 2018. Trade credit and replenishment decisions considering default risk. Computers $\mathcal{E}$ Industrial Engineering 117: 41-46.

Tsuruta, Daisuke. 2015. Bank loan availability and trade credit for small businesses during the financial crisis. Quarterly Review of Economics and Finance 55: 40-52. [CrossRef]

Valvonis, Vytautas. 2008. Credit Risk Assessment and Management Model: Practice and Perspectives of Lithuanian Banks. Ph.D. dissertation, Vilnius University, Vilnius, Lithuania; 204p.

Verbraken, Thomas, Cristian Bravo, Richard Weber, and Bart Baesens. 2014. Development and application of consumer credit scoring models using profit-based classification measures. European Journal of Operational Research 238: 505-13. [CrossRef]

Wang, Kai, Ruiqing Zhao, and Jin Peng. 2018. Trade credit contracting under asymmetric credit default risk: Screening, checking or insurance. European Journal of Operational Research 266: 554-68. [CrossRef]

Xiao, Hongshan, Zhi Xiao, and Yu Wang. 2016. Ensemble classification based on supervised clustering for credit scoring. Applied Soft Computing 43: 73-86. [CrossRef]

Yang, Chenguang, and Xiao-Bo Duan. 2008. Credit Risk Assessment in Commercial Banks Based on SVM Using PCA. Machine Learning and Cybernetics 2: 1207-11.

Yap, Bee Wah, Seng Huat Ong, and Nor Huselina Mohamed Husain. 2011. Using data mining to improve assessment of credit worthiness via credit scoring models. Expert Systems with Applications 38: 13274-83. [CrossRef]

Yoshino, Naoyuki, and Farhad Taghizadeh-Hesary. 2014. Analytical framework on credit risks for financing small and medium-sized enterprises in Asia. Asia-Pacific Development Journal 21: 1-21. [CrossRef]

Zavgren, Christine. 1985. Assessing the Vulnerability to Failure of American Industrial Firms: A Logistic Analysis. Journal of Business Finance E Accounting 12: 19-45.

Zhu, You, Chi Xie, Bo Sun, Gang-Jin Wang, and Xin-Guo Yan. 2016. Predicting China's SME Credit Risk in Supply Chain Financing by Logistic Regression, Artificial Neural Network and Hybrid Models. Sustainability 8: 433. [CrossRef]

(C) 2019 by the authors. Licensee MDPI, Basel, Switzerland. This article is an open access article distributed under the terms and conditions of the Creative Commons Attribution (CC BY) license (http://creativecommons.org/licenses/by/4.0/). 